\title{
Proton Beam Therapy
}

\author{
An Expert Interview with Jason Lester \\ Rutherford Cancer Centre South Wales, Newport, UK
}

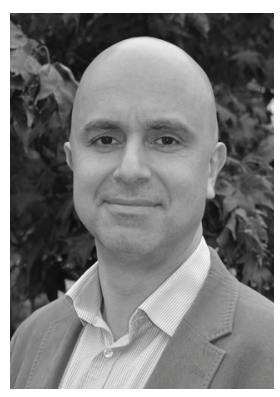

DOI: https://doi.org/10.17925/EOH.2018.14.2.82

\section{Jason Lester}

Dr Jason Lester is a senior consultant clinical oncologist specialising in lung cancer and urological cancers. Following medical training in London and oncology training in Cardiff, UK, Dr Lester has been a consultant oncologist for 15 years and is currently deputy clinical director of Velindre Cancer Centre, and chairman of the Rutherford Cancer Centre Local Medical Advisory Committee for Wales. He is also the clinical lead for the All Wales Prostate Cancer Brachytherapy Service. Dr Lester has been involved in numerous clinical trials in both lung and urological cancer, and has published extensively in these fields. He is the lead investigator for the I-START trial, which is investigating dose-escalated radiotherapy, and the SKOPOS trial, a vaccine trial in malignant pleural mesothelioma. Dr Lester advises patients on all aspects of the non-surgical treatment of lung cancer, mesothelioma and urological cancers (prostate, kidney, bladder). He is responsible for prescribing and supervising the administration of radiotherapy, radioisotope treatment, cytotoxic chemotherapy and hormone therapy.

\section{Keywords}

Proton beam therapy, PBT, radiotherapy

Disclosure: Jason Lester holds clinics at the Rutherford Cancer Centre Newport and is chair of the Medical Advisory Committee at the Rutherford Cancer Centre. Review Process: This is an expert interview and, as such, has not undergone the journal's standard peer review process.

Acknowledgement: Medical writing assistance was provided by Katrina Mountfort of Touch Medical Media and was supported by Touch Medical Media.

Authorship: The named author meets the International Committee of Medical Journal Editors (ICMJE) criteria for authorship of this manuscript, takes responsibility for the integrity of the work as a whole, and has given final approval for the version to be published.

open Access: This article is published under the Creative commons Attribution Non-commercial License, which permits any non-commercial use, distribution, adaptation, and reproduction provided the original author and source are given appropriate credit. (C) The Author 2018.

Received: 10 September 2018

Published Online: 14 December 2018

Citation: European Oncology \& Haematology,

2018;14(2):82-3

Corresponding Author: Jason Lester, Rutherford Cancer Centre, Celtic Springs Business Park, Spooner Close, Newport, NP10 8FZ.E: jason.lester@therutherford.com

Support: No funding was received in

the publication of this article.
$\mathrm{P}$ roton beam therapy is a type of radiotherapy that employs a high energy beam of protons rather than high energy $\mathrm{X}$-rays to deliver a dose of radiotherapy for patients with cancer.? The UK has been involved in the development of proton beam therapy; a specialist eye service at Clatterbridge, Merseyside, UK, was the first hospital-based proton beam therapy facility, treating eyes with a low-energy proton beam. ${ }^{2}$ High-energy proton beam is now widely available in the US, and is increasingly becoming available in Europe. The procedure received considerable media attention in the UK in 2014, when the parents of a boy with a brain tumour, Ashya King, took the child out of hospital to receive proton beam therapy in Europe. ${ }^{3}$ In 2016 , following the publication of a phase II study, ${ }_{1}^{4}$ the $\mathrm{NHS}$ decided to fund children with medulloblastoma to travel abroad to receive proton therapy. ${ }^{5}$ Earlier in 2018, the Rutherford Cancer Centre in south Wales became the first clinic in the UK to offer high energy proton beam therapy. ${ }^{6}$ Two other facilities are currently being built at The Christie NHS Foundation Trust in Manchester and University College London Hospital NHS Foundation Trust, and services are expected to commence within the next 2 years. ${ }^{5}$ In an expert interview, Jason Lester of the Rutherford Cancer Centre, discusses the advantages and limitations of this therapy.

\section{Q. What are the major unmet needs in radiotherapy in cancer treatment?}

Cancer incidence is rising because of the drive to diagnose patients more quickly and treat them earlier. Because of this, the indications for radiotherapy are increasing and we are treating more patients; for example, stereotactic radiotherapy is used for early stage lung cancer, which was not the case 10 years ago. One of the major challenges is, therefore, the need to increase our radiotherapy capacity due to increasing demand. In addition, treatment complexity is increasing, which increases the time needed to plan and deliver radiotherapy treatment. In addition, we need investment in state-of the-art machines to deliver this technical treatment, and we need enough staff with appropriate expertise to oversee, plan and deliver the treatment. In the current economic climate, expanding and upgrading radiotherapy services in the UK is difficult, but progress is being made.

\section{Q. What are the advantages of proton beam therapy compared to conventional radiotherapy?}

Conventional radiotherapy uses high energy X-rays called photons to destroy cancer cells, while proton beam therapy uses beams of protons to achieve the same effect. Unlike conventional radiotherapy, the properties of protons allow them to enter and travel through tissue with minimal dose deposition on the way to the target. When they reach the target, they stop almost immediately, meaning that there is minimal exit dose. This means that proton beam can reduce the risk of serious side effects and the severity of side effects. 


\section{Q. Which patients are likely to benefit most from this treatment?}

Proton beam therapy is currently the preferred option for treating solid tumours in children because there is almost always less radiation dose to normal tissues, and this reduces the chance of serious complications. Importantly, this also reduces the risk of secondary radiation-induced cancers developing later. In adults, proton beam therapy is used to treat cancers that are located near critical structures such as the optic nerve or spinal cord where conventional X-ray treatment may cause damage. Proton beam therapy can be effective in treating a range of other cancers including head and neck, lung, prostate, breast, bowel and rectal cancers. It can also be useful to treat cancers that have relapsed after receiving a radical dose of radiotherapy.

\section{Q. What are the limitations of proton beam therapy?}

There are no reported randomised trials that have compared proton beam therapy to conventional radiotherapy, so quantifying the benefit of treatment can be difficult. From a technical point of view, any change in tissue composition such as variations of the setup of the patient on the treatment machine, lung expansion or rapid shrinkage of the tumour, may affect the target dosage and proton dose to the surrounding structures. The effect of changing tissue composition is not specific to proton beam therapy, but the influence of tissue change on dose is more pronounced with protons than with photons. Organ motion, such as respiratory movement in the chest, can have a greater impact on dose with proton beam therapy. It is important to take great care when positioning a patient for proton beam therapy; treatment verification with cone beam computed tomography in the head of the instrument is very important prior to each treatment.

\section{Q. What further clinical evidence is needed to support the cost-effectiveness of proton beam radiotherapy?}

As with all newer cancer therapies, there is a need to carry out clinical trials comparing proton beam therapy to conventional radiotherapy and potentially other cancer treatments, depending on the clinical situation. Clearly, such trials would be complex, expensive and time-consuming, particularly as the number of proton beam therapy centres in the UK will be small, even in a few years' time. $\square$

Wang D. A critical appraisal of the clinical utility of proton therapy in oncology. Med Devices (Auckl). 2015:8:439-46.

The Christie NHS Foundation Trust. Development of proton beam therapy. Available at: www.christie.nhs.uk/services/i-to-q/protons/what-is-proton-beam-therapy/development-of-proton-beam-therapy/ accessed 10 september 2018).

(accessed 10 September 2018).

Yock TI, Yeap BY, Ebb DH, et al. Long-term toxic effects of proton radiotherapy for paediatric medulloblastoma: a phase 2 single-arm study. Lancet Oncol. 2016;17:287-98.

NHS England. Proton beam therapy. Available at: www.england.nhs.uk/commissioning/spec-services/highly-spec-services/pbt/ (accessed 10 September 2018).

Rutherford Cancer Centres. First cancer patient treated with high energy proton therapy in the UK. Available at: www.therutherford.co.uk/news/first-cancer-patient-treated-with-high-energy-proton-therapy-in-the-uk/ (accessed 10 September 2018) 